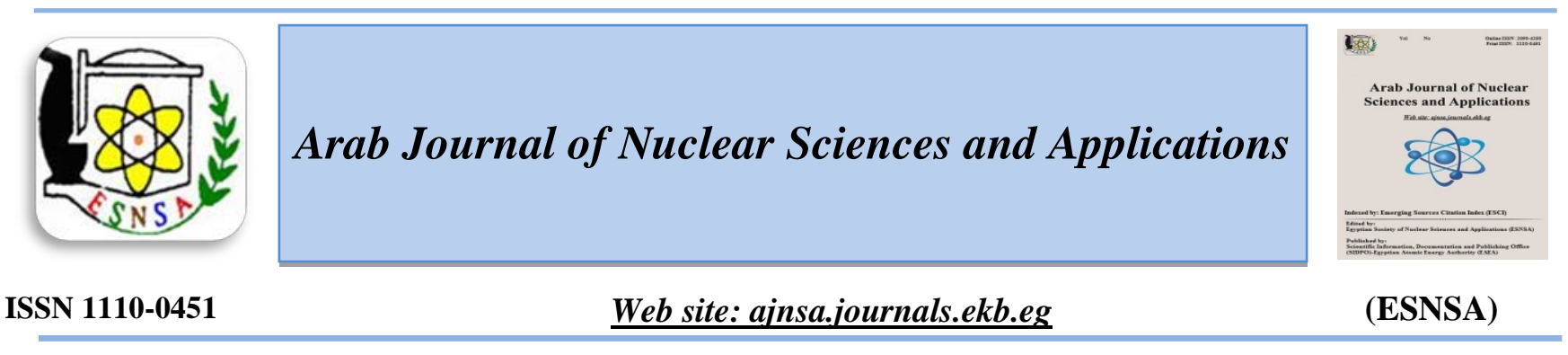

\title{
Ionizing Radiation effect on Teucrium polium: Phytochemical Contents, Antioxidant and Antibacterial Activity
}

\author{
Saif M. Dmour ${ }^{1}$, M. Easa ${ }^{2}$, N. A. Eltahawy ${ }^{3}$, S. M. Elsonbaty ${ }^{3}$ \& H.N. Qaralleh ${ }^{{ }^{*}}$ \\ ${ }^{1}$ Department of medical and laboratory sciences, Faculty of Science, Mutah University, Karak, Jordan \\ ${ }^{2}$ Microbiology Department, Faculty of Science, Ain Shams University, Cairo, Egypt \\ ${ }^{3}$ National Center for Radiation Research and Technology, Atomic Energy Authority, Cairo, Egypt
}

\begin{abstract}
Received 24 $4^{\text {th }}$ July 2019 Medicinal plants providing natural products may be used as precursors for new drugs for their Accepted $15^{\text {th }}$ March chemical diversity. In the present study, the potential of gamma radiation as sterilizing agent for preservation and its effect on phytochemical contents, antioxidant and antibacterial activity of Teucrium polium (T. polium) was analyzed for antimicrobial activity. The results revealed that exposing plant powder to doses of gamma irradiation $(5,10,15 \& 20 \mathrm{kGy})$ significantly increased the ethyl acetate extraction yield (dry weight) as compared to the non-irradiated plant (control). Teucrium polium phytochemical contents of total phenolic content (TPC), total flavonoids content (TFC) and tannins content were significantly increased with gamma irradiation. In the same line, the antioxidant activity was significantly increased in response to radiation dose. Teucrium polium showed antibacterial activity against Pseudomonas aeroginosa and Staphylococcus aureus. Gamma irradiation significantly increased the antibacterial activity against $P$. aeroginosa and $S$. aureus at dose of $20 \mathrm{KGy}$ compared to other doses. The microbial load total count of $T$. polium was significantly reduced by exposure to gamma radiation (5, 10, 15 \& $20 \mathrm{kGy})$. Exposure to $5.0 \mathrm{kGy}$ significantly reduced the bacterial count by $99 \%$ while fungi count was not detected, while exposure to $10 \mathrm{kGy}$ was enough to eliminate bacteria and fungi from plant sample.
\end{abstract}

Keywords: Teucrium polium, Gamma irradiation, Antibacterial activity, phytochemical

\section{Introduction}

Ionizing Gamma radiation has been widely used as a safe decontamination process for many years, being applied to several types of foods including medicinal plants, which may affect plant chemical constituents and bioactivity.

Teucrium polium L. (Ja'adeh) has been known as an important traditional medicinal plant in Jordan. It is a wild-growing flowering perennial herbaceous plant which belongs to the family Lamiaceae [1]. It's a flowering plant, which grows in the dry rocky areas and stony places of the hills, mountains and deserts of almost all Mediterranean countries, South Western Asia, Europe and North
Africa [2]. Hot infusion of aerial parts of T. polium has been used by many Jordanians and other people in Mediterranean countries in folk medicine for anti-inflammatory, gastrointestinal disorders, abdominal colic, diabetes, kidney stones, headache, hypoglycemic, as well as vermifuge, appetizer, expectorant, wound healing, stomach ulcer, chills, fever, earthworms, healing wound and other disorders[3]. Additionally, the plant reduces high body weight and high blood pressure and is lipid-lowering [4]. However, the Biological properties of Teucrium polium also include antioxidant [5], antidiabetic effects [6], antiseptic [7], antihypertensive [8], Hypolipidemics [9]

Corresponding author: sawsan.sonbaty@eaea.org.eg

DOI: 10.21608/ajnsa.2020.15218.1242

(C) Scientific Information, Documentation and Publishing Office (SIDPO)-EAEA 
anticancer effect [10], antidiabetic [11] and antiinflammatory activity [12] Many researchers showed that the plants belonging to the genus Teucrium are rich in flavonoids, phenolic acid [13,14], phenylpropanoid glycosides, tannins, sterol [15] iridoid, fatty acid [16], monoterpenes,[17], sesquiterpenes, sterols, saponins and iridoid glycoside [18], and diterpenes [19]. Many reports showed that microbial contamination of plants, which occur during cultivation, harvest, processing and storage, may affect the chemical composition, and they may have an important role in determining the bioactivity and chemical composition [20].

Gamma radiation is a suitable food preservation technique for improving the safety of a wide range foods and their shelf life, by eliminating pathogenic and reduce the number of spoilage microorganisms without altering the biological or nutrition quality of the food and the physiological and biochemical process in plant [21]. The present work aims to study the effect of gamma irradiation on Teucrium polium: microbial load, phytochemical contents as well as antioxidant and antimicrobial activity.

\section{MATERIALS AND METHODS}

\section{Plant materials}

Teucrium polium was collected from Adnaniah, Karak city (the south of Jordan) during May and June of 2017 when plants were at the late flowering stage, (position: $31^{\circ} 11^{\prime}$ 88.31" N (Latitude), 3570'9608" E (Longitude). The plants was identified by Dr. Saleh Alquran, Biology department, college of science, Mu'tah University, Jordan.

The collected plants were dried in the shadow at ambient temperature $\left(25^{\circ} \mathrm{C}\right)$ for enough time until the mass was stabilized, then grinded to a fine powder and stored in clean polyethylene bags away from light and moisture.

\section{Gamma irradiation}

The powder of the dry plants were irradiated at a dose level of $(5,10,15$, and $20 \mathrm{KGy})$ in the Gamma chamber 4000-A India, irradiation facility, at the National Center for Radiation Research and Technology (NCRRT), Atomic Energy Authority, Cairo, Egypt at a dose rate of $1.170 \mathrm{kGy} / \mathrm{h}$.

\section{Microorganisms}

The antibacterial potency of $T$. polium extract was evaluated using Gram-positive strain (Staphylococcus aureus (ATCC 25923) and Gramnegative strain (Pseudomonas aeroginosa (ATCC 27853). These were obtained from the Regional Center for Mycology and Biotechnology, Faculty of Science, Al-Azhar University, Cairo, Egypt.

\section{Preparation of bacterial culture}

Fresh bacterial cultures were prepared by subculturing stock bacterial cultures into freshly prepared nutrient agar and incubating at $37^{\circ} \mathrm{C}$ for 24 hours. These microbial cultures were transferred into freshly prepared nutrient broth and standardized using the method of ( 0.5 McFarland turbidity standards) using the spectrophotometer (SCO TECH SPUV-19- Germany) to obtain the desired cell density of $1.5 \times 10^{8}$ (cells/ml).

\section{Preparation of Teucrium polium extract}

Dry powder $(50.0 \mathrm{~g})$ of each $T$. polium sample was immersed in $150 \mathrm{ml}$ of ethyl acetate for 72 hours at room temperature $\left(27^{\circ} \mathrm{C}\right)$ [22]. Plant extracts were dried by evaporating solvents using rotary evaporator and the extraction yield (\%) is calculated by the formula below:

$$
\begin{aligned}
& \text { Yield of extract } \% \\
& =\frac{\text { extract dry weight }}{\text { plant powder dry weight }} \times 100
\end{aligned}
$$

Hundred milligrams from the crude extract was dissolved in $1 \mathrm{~mL}$ of $10 \%$ DMSO. The extract was clarified by filtration through sterile syringe filter with 0.2-0.45 $\mu \mathrm{m}$ pore and stored in a refrigerator at $4^{\circ} \mathrm{C}$ as aliquots for further uses.

\section{Phytochemical contents:}

\section{Determination of Total Phenolic Contents (TPC)}

The total phenolic contents of T.polium extract were determined by folin-ciocalteau reagent method according to [23]. $0.1 \mathrm{ml}$ of diluted extract was transferred into a test tube and the volume was made up to $8 \mathrm{ml}$ with distilled water. Then, $0.5 \mathrm{ml}$ Folin- Ciocalteus phenol reagent was added, followed by $1.5 \mathrm{ml}$ of $20 \%$ aqueous sodium carbonate solution. Tubes were vortexed, incubated at room temperature $\left(27^{\circ} \mathrm{C}\right)$ for $30 \mathrm{~min}$. and the absorbance of blue colored mixture was determined at 765nm (SCO TECH SPUV-19Germany) against a blank solution prepared by 
adding $0.1 \mathrm{ml}$ of solvent instead of the tested sample. Based on the measured absorbance, the concentration of phenolic content was determined from the standard curve of Gallic acid and expressed as Gallic equivalent (mg Gallic acid/g dry extract).

\section{Determination of Total Flavonoid Contents (TFC):}

The total flavonoid contents of T.polium extract were determined using aluminium chloride complex according to the method adopted by [24].100 $\mu \mathrm{l}$ of T.polium extract was mixed with $500 \mu \mathrm{l}$ of distilled water and then $100 \mu \mathrm{l}$ of $5 \%$ Sodium nitrate was added and allowed to stand for 6 minutes. Then $150 \mu \mathrm{l}$ of $10 \%$ Aluminium chloride solution was added and allowed to stand for 5 minutes. After which $200 \mu \mathrm{l}$ of $1 \mathrm{M}$ Sodium hydroxide solution was added sequentially. The absorbance of this reaction mixture was recorded at $510 \mathrm{~nm}$ using UV spectrophotometer (SCO TECH SPUV-19-Germany). Total flavonoid concentrations were calculated using rutin as a standard curve. Concentration of flavonoids in the extracts was expressed in terms of rutin equivalent (mg of rutin/g dry extract).

\section{Determination of Tannins content (TC):}

Tannins concentration of $T$. polium ethyl acetate extract was determined according to the method of (Polshettiwar, Ganjiwale et al., 2007) [25] as follows: a volume of $100 \mu \mathrm{L}$ of diluted extract was added to $7.5 \mathrm{~mL}$ of a distilled water and $0.5 \mathrm{~mL}$ of folin reagent and $1 \mathrm{ml}$ of $\mathrm{Na}_{2} \mathrm{CO}_{3}(35 \%)$. After $30 \mathrm{~min}$ of incubation, the absorbance was determined spectrophotometrically using (SCO TECH SPUV-19-Germany) at 700 $\mathrm{nm}$. The Total tannins content was calculated using tannic acid standard curve and expressed as (mg tannic acid/g dry extract).

\section{Free radical scavenging activity}

The antioxidant activity of $T$. polium ethyl acetate extract was determined by the 2,2Diphenyl-1-picrylhydrazyl (DPPH) free radical scavenging assay. The hydrogen atom or electron donation abilities of the plant extracts to scavenge DPPH free radicals were assessed [26].

Freshly prepared $(0.004 \% \mathrm{w} / \mathrm{v})$ ethanol solution of DPPH radical was used. A $40 \mu$ aliquot of T.polium extract dissolved in ethanol solution was added to $3 \mathrm{ml}$ of the DPPH solution. Absorbance measurements were recorded immediately using a UV-visible spectrometer. The decrease in absorbance at $517 \mathrm{~nm}$ was determined continuously, with data being recorded at $1 \mathrm{~min}$ intervals until the absorbance stabilized (16 min). The absorbance of the DPPH radical (control) and the reference compound ascorbic acid were also measured. All the determinations were performed in three replicates.

The percentage inhibition (PI) of the DPPH radical was calculated according to the formula:

$$
P I=\frac{A C-A T}{A C}
$$

Where $A C=$ Absorbance of the control at $\mathrm{t}=0 \mathrm{~min}$ and $A \mathrm{~T}=$ absorbance of the sample $+\mathrm{DPPH}$ at $\mathrm{t}=$ 16 min

The $50 \%$ inhibitory concentration $\left(\mathbf{I C}_{\mathbf{5 0}}\right)$ that is the concentration required to inhibit DPPH radical by $50 \%$, was estimated from graphic plots of the dose response curve.

\section{Antibacterial activity assay}

The antibacterial activity of non-irradiated and irradiated (5, 10, 15 and $20 \mathrm{kGy})$ was assessed by agar well diffusion method reported by Murray et al. [27]against $S$. aureus and $P$. aeruginosa. Briefly, $100 \mu \mathrm{l}$ of bacterial inoculum containing $1.5 \times 10^{8} \mathrm{CFU} / \mathrm{mL}$ was spread on nutrient agar plates. Then, the wells were made by using a sterile cork borer in the media and then $100 \mu \mathrm{l}(10$ $\mu \mathrm{g})$ of the extracts were placed into each well. Standard reference antimicrobial discs of (Gentamycin) were used as a positive control and solvent (10\% DMSO) loaded well was also used as negative control. Plates which inoculated with bacteria were incubated at $37{ }^{\circ} \mathrm{C}$ for $24 \mathrm{hrs}$, then the inhibition zone was measured in $\mathrm{mm}$.

Evaluation of minimum inhibitory concentration (MIC)

The MIC of non-irradiated and irradiated $T$. polium extract was determined according to the well diffusion method [27]. A $100 \mu \mathrm{l}$ of (P. aeroginosa and $S$. aureus) inoculum containing 1.5 $\mathrm{X} 10^{8} \mathrm{CFU} / \mathrm{mL}$ was spread on nutrient agar plates with different concentrations of $T$. polium extracts (2, 4, 6, 8 and $10 \mathrm{mg} / \mathrm{ml}$ ) dissolved in DMSO were placed into each well. The plates were subsequently incubated at $37^{\circ} \mathrm{C}$ for $24 \mathrm{hrs}$. After 
incubation the growth inhibition zone was measured in $\mathrm{mm}$.

\section{Determination of T.polium microbial load}

The microbial load of both irradiated and nonirradiated plants was determined using serial dilution method [28], where $1 \mathrm{gm}$ of T.polium sample was mixed with $9 \mathrm{ml}$ sterile saline $(0.9 \%)$ and mixed well. $1 \mathrm{ml}$ of mixed saline was pipetted to $9 \mathrm{ml}$ of saline and serial dilutions were prepared consequently. $0.1 \mathrm{ml}$ of each dilution was poured and spread on nutrient agar plate $\left(30^{\circ} \mathrm{C}\right)$ for 48 hours and potato dextrose agar plate $\left(25^{\circ} \mathrm{C}\right)$ for 5 days. The developing colonies were counted, and the Total Bacterial counts (TBC) and Total Fungal Count (TFC) were expressed as colony forming units (cfu) per gram of plant sample.

\section{Statistical analysis}

Results are expressed as means \pm standard deviations from triplicate measurements. The Statistical Package for Social Sciences (SPSS, version 20 for windows) was used to analyze the data. The means were compared using Duncan's multiple range (DMRT) test at $p<0.05$ following analysis of variance (ANOVA).

\section{RESULTS}

Effect gamma radiation on the extraction yield

The extraction yields of ethyl acetate $T$. polium extract were determined at various doses of gamma irradiation and results are given in Figure (1). Yield percentages of non-irradiated and irradiated T. polium were ranged from 2.80 to $3.38 \%$. While, non-irradiated $T$. polium (Control sample) gave a yield of $2.84 \%$, the gamma radiation with dosages from $5 \mathrm{kGy}$ to $15 \mathrm{kGy}$ increased the extraction yield to $2.90,3.28$ and $3.38 \%$ respectively. On the other hand, 20 KGy decreased the extraction yield to $(2.8 \%)$ compared to the control.

Total flavonoids content (TFC):

The results showed that changes in TFC of the $T$. polium extract under different doses of gamma irradiation recorded a significant increase compared to the control plants. The TFC values were significantly increased with the increase of gamma radiation doses, with percentage of 36.31, 69.87, 74.14 and $82.25 \%$ at doses of 5, 10, 15 and $20 \mathrm{kGY}$, respectively compared to the control (non-irradiated), Figure (2).

\section{Tannins content (TC):}

Our results revealed that, TC values of T.polium were significantly increased with increasing doses of gamma irradiation. Gamma irradiation significantly increased TC at 5, 10, 15 and $20 \mathrm{kGy}$ with percent of change 17.50, 140.66, $141.74,150.38 \%$ respectively as compared to the control samples (Figure 3).

\section{Antioxidant activity:}

The DPPH and $\mathrm{IC}_{50}$ value of the gamma irradiated and non-irradiated (control) of $T$. polium extracts are presented in Figures (4\&5). The antioxidant activities of the non- irradiated T.polium were increased significantly when increasing the extract concentrations (200 to 1000 $\mu \mathrm{g} / \mathrm{ml})$. Gamma irradiation results in a significant increase of antioxidant activity of T.polium extract at different doses. At $400 \mu \mathrm{g} / \mathrm{ml}$, the irradiation doses resulted in a slight increase in the antioxidant activity of $T$. polium extract 11.78 , 17.66, 25.90 and $47.08 \%$ for 5, 10, 15 and $20 \mathrm{kGy}$ respectively as compared to control. IC $_{50}$ content is decreased significantly under gamma irradiation

A

b

Table (1): Effect of gamma radiation on the extraction yield of $T$. polium

\begin{tabular}{ccc}
\hline $\begin{array}{c}\text { Gamma radiation } \\
\text { (kGy) }\end{array}$ & $\begin{array}{c}\text { Dry yield weight } \\
\text { (mg) }\end{array}$ & $\begin{array}{c}\text { Yield percentage } \\
(\mathbf{\%}, \mathbf{w} / \mathbf{w})\end{array}$ \\
\hline 0 & $426 \pm 23.65$ & 2.84 \\
5 & $435 \pm 35.56$ & 2.90 \\
10 & $492 \pm 38.89^{*}$ & 3.28 \\
15 & $507 \pm 25.70^{*}$ & 3.38 \\
20 & $420 \pm 20.65$ & 2.80 \\
\hline
\end{tabular}




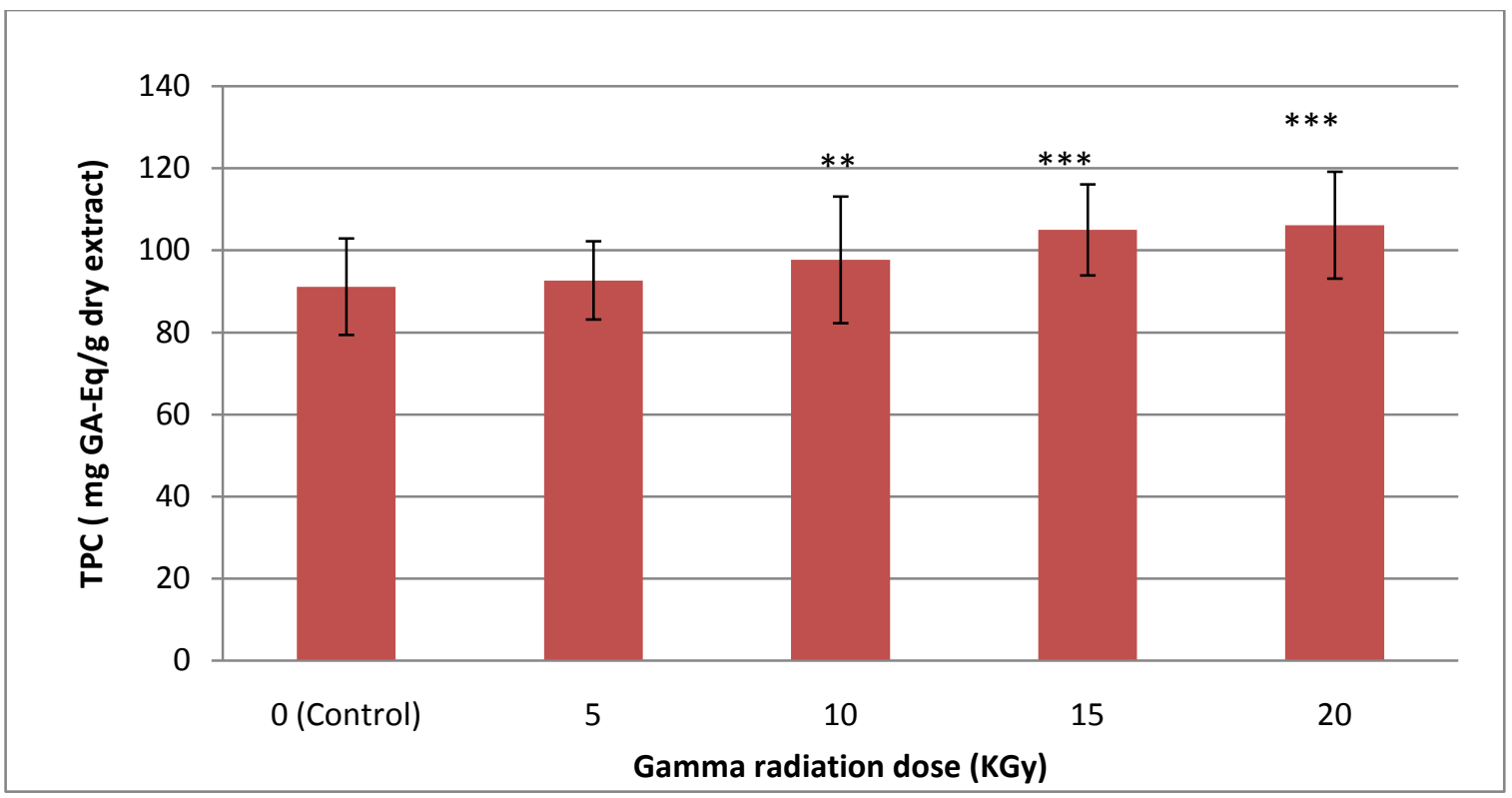

Fig. (1): Effect of gamma radiation on total phenolic content of $T$. polium.

Each value represents the mean of triplicate $(\mathrm{n}=3) \pm$ S.D. ${ }^{* *}=$ high significant $(\mathrm{P} \leq 0.01)$.

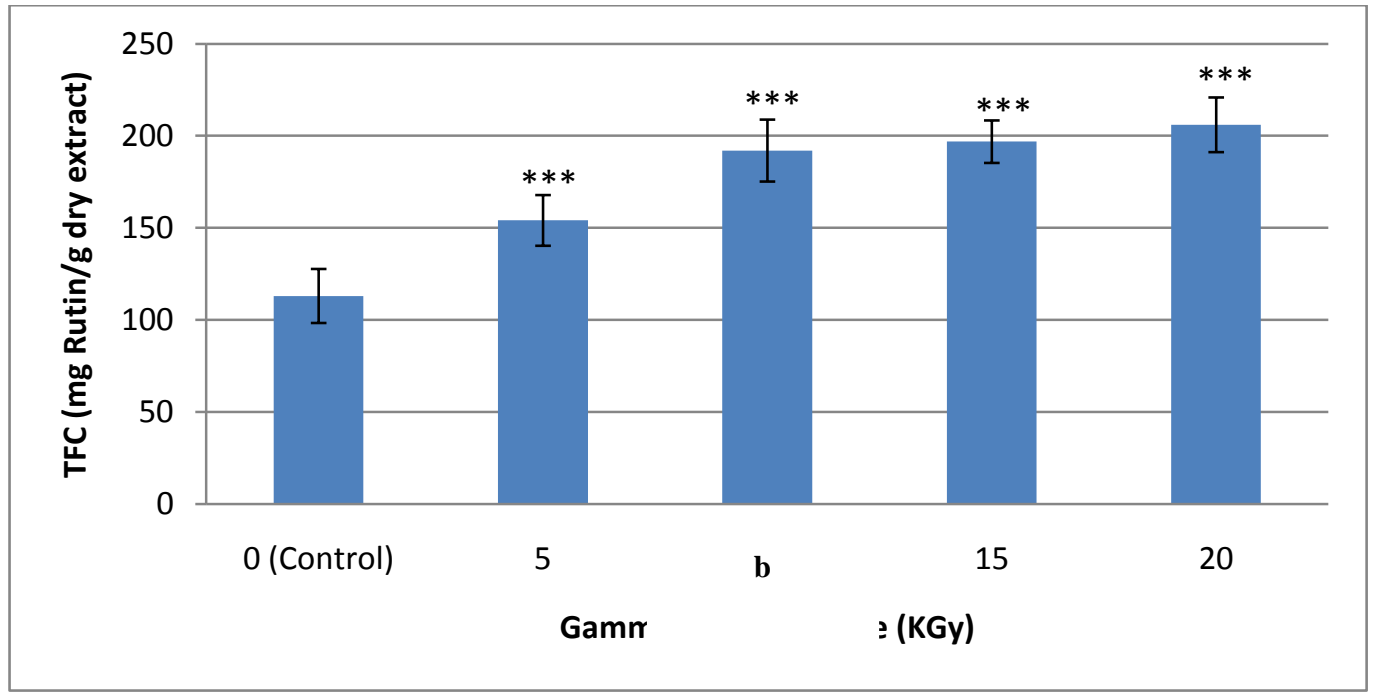

Fig. (2): Effect of gamma radiation on total flavonoids content of T. polium.

Each value represents the mean of triplicate $(\mathrm{n}=3) \pm$ S.D. $(* * *)$ indicate very high significant $(\mathrm{P} \leq 0.01)$. 


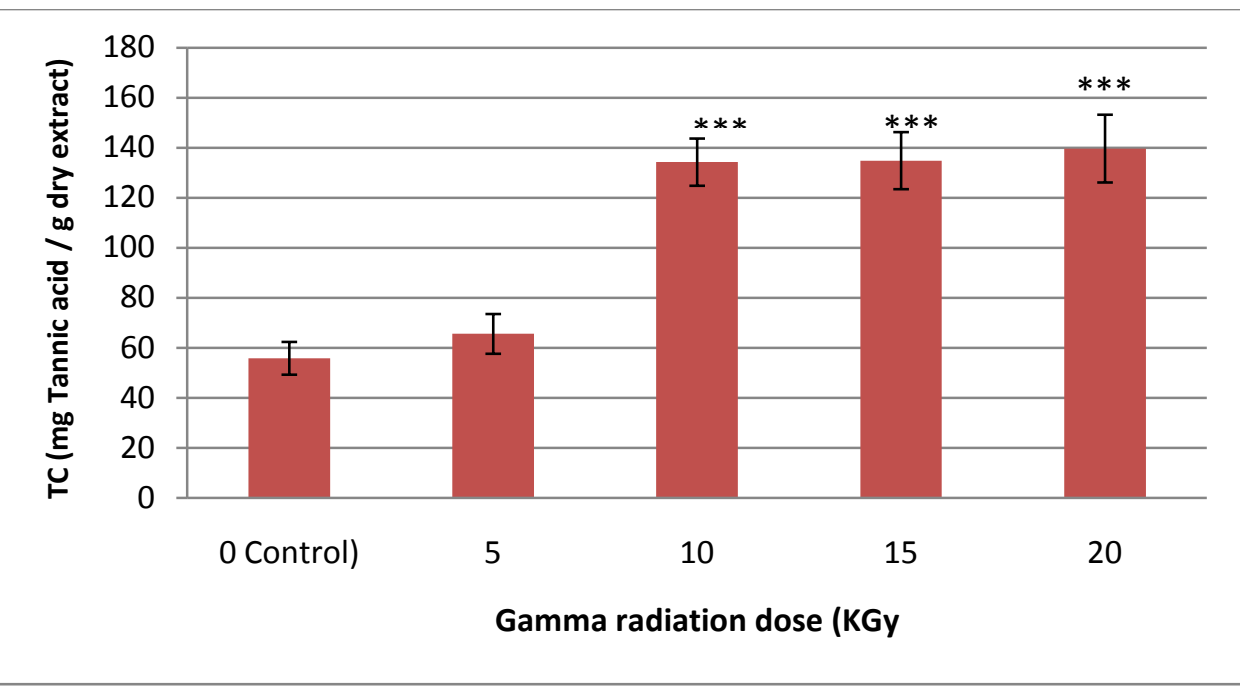

Fig. (3): Effect of gamma radiation on tannins content of $T$. polium Each value represents the mean of triplicate $(\mathbf{n}=3) \pm$ S.D. $(* * *)$ indicate very high significant $(\mathbf{P} \leq \mathbf{0 . 0 1})$.

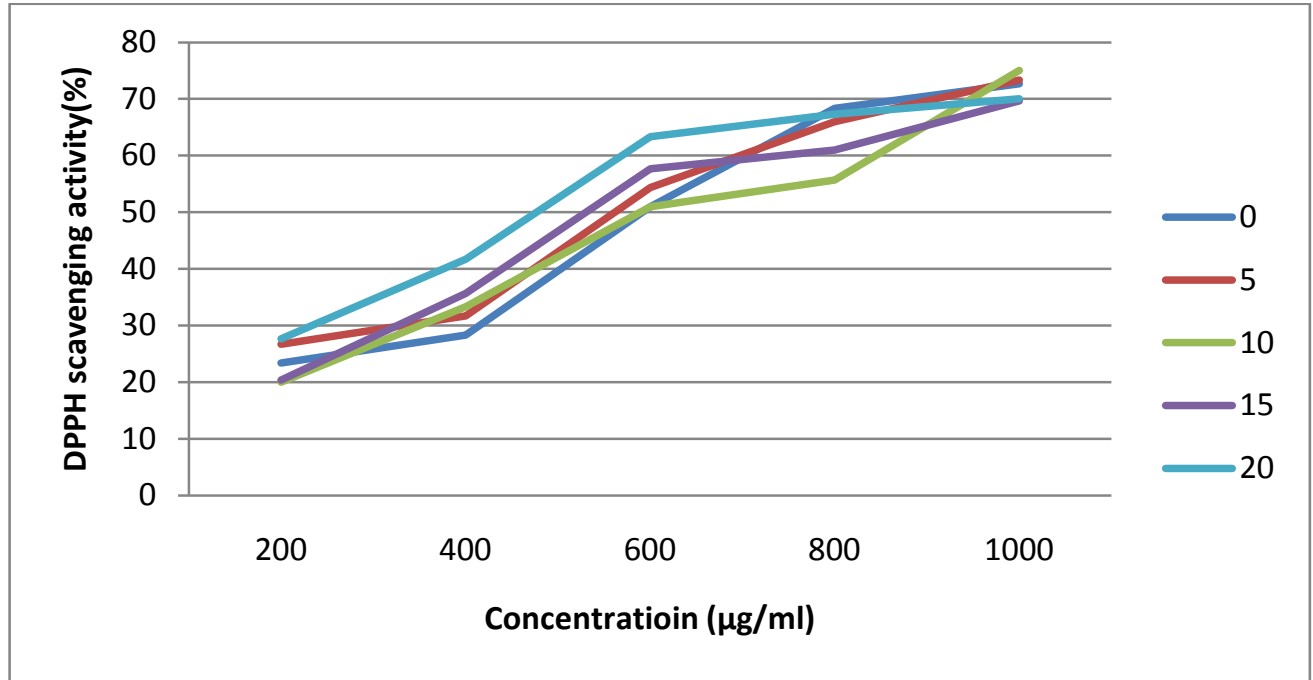

Fig. (4): Effect of gamma irradiation on the DPPH scavenging activity of T. polium. Each value represents the mean of triplicate $(n=3) \pm$ S.D 


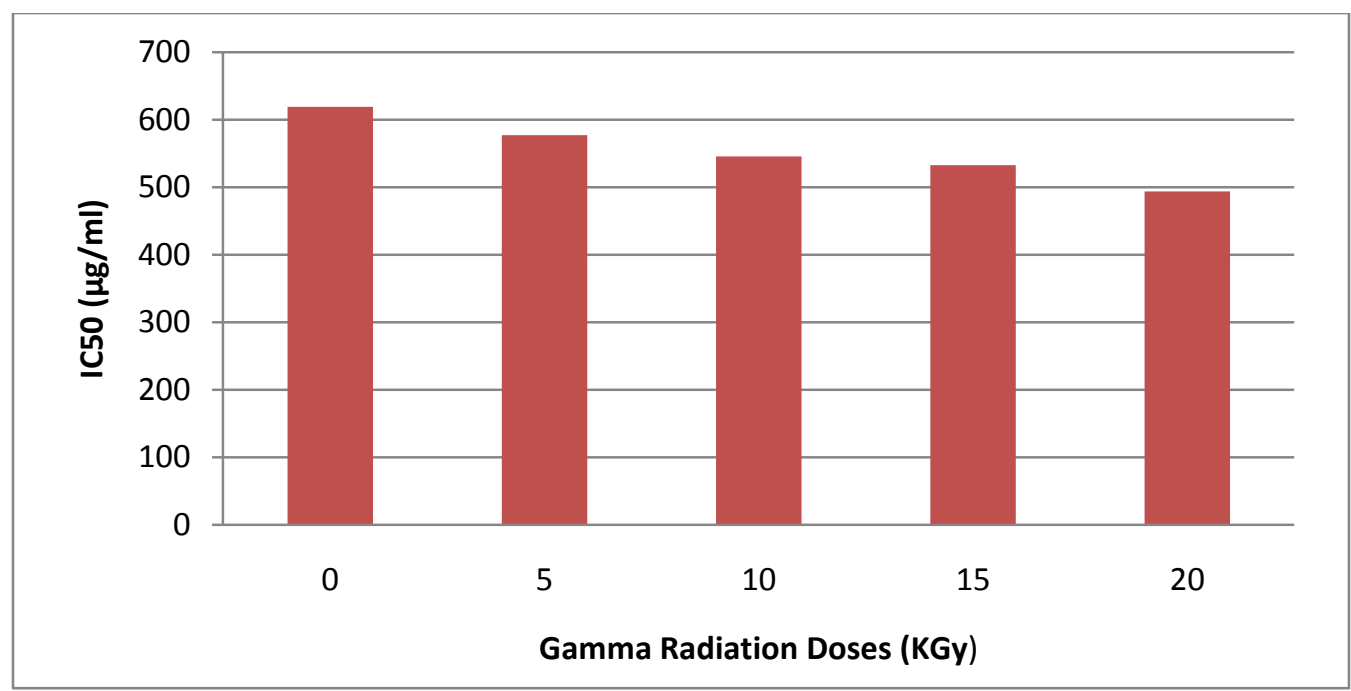

Fig. (5): Radical scavenging activity $\mathrm{IC}_{50}$ of T.polium

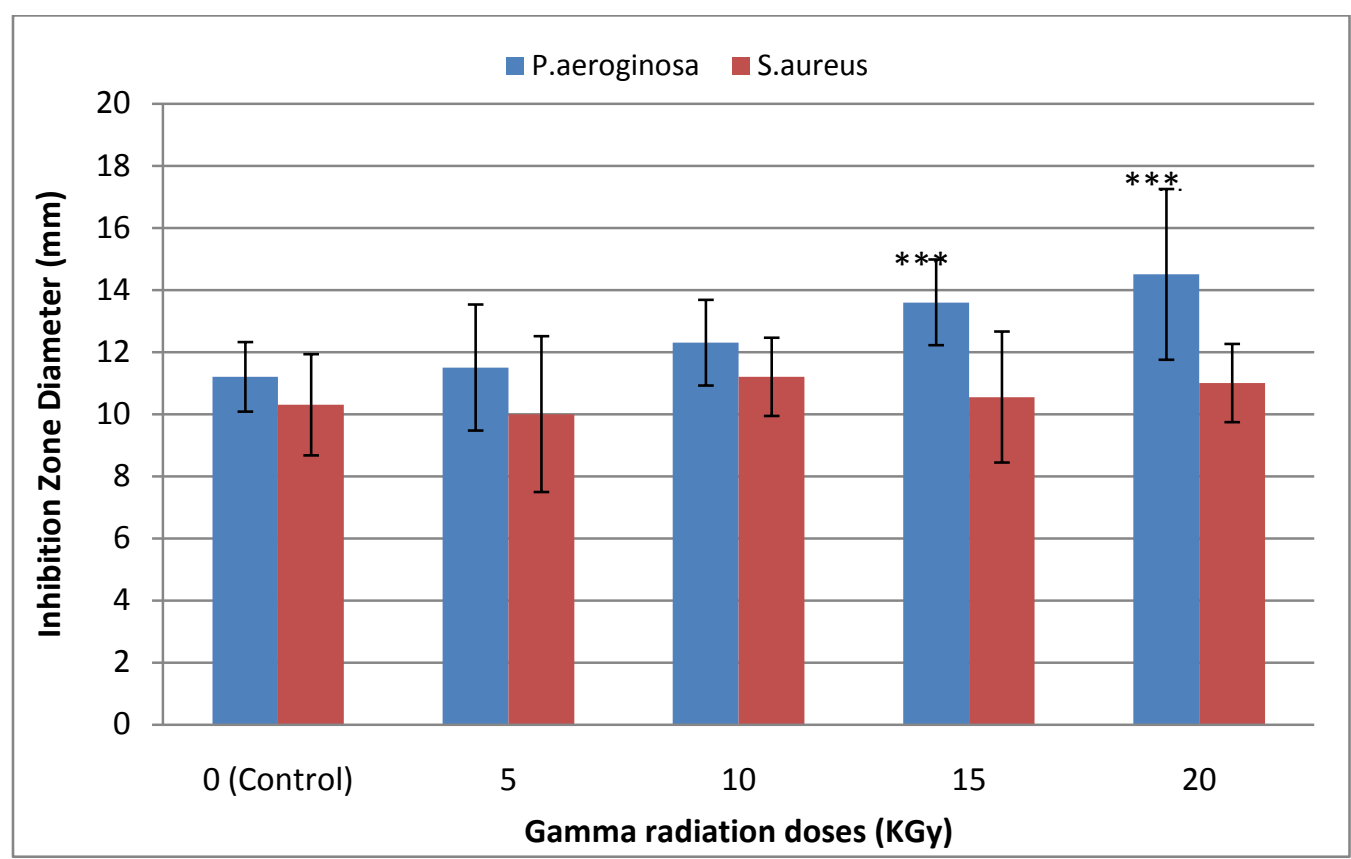

Fig. (6): Effects of gamma radiation on the antibacterial activity of $T$. polium. Each value represents the mean of triplicate $(\mathrm{n}=3) \pm$ S.D. $\left({ }^{* * *}\right)$ indicate very

high significant $(\mathrm{P} \leq 0.01)$

Table (2): Minimum inhibitory concentrations (MIC) of non- irradiated and irradiated (20 kGy) Teucrium polium against $P$. aeruginosa and S.aureus

\begin{tabular}{|c|c|c|c|c|}
\hline \multirow{3}{*}{$\begin{array}{l}\text { Concentration } \\
(\mathrm{mg} / \mathrm{ml})\end{array}$} & \multicolumn{4}{|c|}{ Inhibition Zone (mm) } \\
\hline & \multicolumn{2}{|c|}{$\begin{array}{c}\text { Non-irradiated plant extract } \\
\text { (0 kGy) }\end{array}$} & \multicolumn{2}{|c|}{$\begin{array}{c}\text { Irradiated plant extract } \\
(20 \mathrm{kGy})\end{array}$} \\
\hline & S.aureus & P. aeruginosa & S.aureus & P. aeruginosa \\
\hline 2 & NA & $6.20 \pm 0.66$ & NA & NA \\
\hline 4 & NA & $6.30 \pm 1.20$ & $6.30 \pm 1.40$ & $7.50 \pm 1.10$ \\
\hline 6 & NA & $7.60 \pm 1.57$ & $7.80 \pm 1.80$ & $9.00 \pm 1.45$ \\
\hline 8 & $9.20 \pm 1.66$ & $9.25 \pm 2.06$ & $8.50 \pm 2.20$ & $10.25 \pm 0.54$ \\
\hline 10 & $10.70 \pm 1.00$ & $11.50 \pm 1.90$ & $9.40 \pm 2.18$ & $12.40 \pm 0.98$ \\
\hline 12 & $10.30 \pm 0.45$ & $12.25 \pm 2.10$ & $10.10 \pm 1.79$ & $13.00 \pm 1.40$ \\
\hline
\end{tabular}


Table (3): Effects of various doses of gamma irradiation on the on microbial load (CFU/g) of Teucrium polium powder

\begin{tabular}{|c|c|c|c|c|c|}
\hline \multirow{2}{*}{$\begin{array}{c}\text { Total count } \\
\text { (CFU/g) }\end{array}$} & \multicolumn{5}{|c|}{ Irradiation dose (kGy) } \\
\hline & 0 (control) & 5 & 10 & 15 & 20 \\
\hline TBC & $8.2 \times 10^{4}$ & $4.0 \times 10^{2}$ & $<10$ & $<10$ & $<10$ \\
\hline TFC & $3.1 \times 10^{4}$ & $<10$ & $<10$ & $<10$ & $<10$ \\
\hline
\end{tabular}

TBC: Total bacterial count, TFC: Total fungi count. $<10$ : Not detected (detection limit $>10 \mathrm{CFU} / \mathrm{g}$ ). Each value represents the mean \pm S.D. $(n=3)$.

\section{Antibacterial activity}

The antibacterial activity of ethyl acetate extract of non-irradiated and irradiated T. polium

against $\mathrm{P}$. aeruginosa and $\mathrm{S}$. aureus are displayed in Figure (6). Non-irradiated T.polium was of moderate antibacterial activity against $P$. aeruginosa and S.aureus producing inhibition zone diameter $(11.20,10.30 \mathrm{~mm})$ respectively.

Irradiation significantly increased antibacterial activity of T.polium against P.aeroginosa. The inhibition zone was increased by the effect of gamma radiation. On the other hand, it could be noted that irradiation did not affect the antibacterial activity against S.aureus, where, the inhibition zone in the control sample was 10.30 $\mathrm{mm}$, the largest inhibition zone was $20 \mathrm{~mm}$ at irradiation dose of $10 \mathrm{kGy}$, while the smallest inhibition zone was $9.40 \mathrm{~mm}$ at irradiation dose 20 kGy. The minimum inhibitory concentration (MIC) of T. polium against P.aeroginosa and S.aureus was determined by the well diffusion. As it can be seen in Table (2), different concentrations (2, 4, 6, 8, 10 and $12 \mathrm{mg} / \mathrm{ml})$ of non-irradiated and irradiated plant extracts were investigated to determine their MICs against test microorganisms. Our results showed that the minimum inhibitory effect of non-irradiated $T$. polium extract was at 8 $\mathrm{mg} / \mathrm{ml}$ and $<2 \mathrm{mg} / \mathrm{ml}$ with inhibition zones of 9.20 and $6.20 \mathrm{~mm}$ against $S$. aureus and $P$. aeruginosa respectively, while irradiated $T$. polium suppressed bacterial growth of these strains at concentration of $4 \mathrm{mg} / \mathrm{ml}$ with inhibition zones of 6.30and $7.50 \mathrm{~mm}$ respectively.

\section{Effect of gamma irradiation on T.polium microbial load}

Microbial counts (total bacterial counts and total fungal counts) were measured by pour plate method in control and irradiated T.polium powder. The initial mean populations of the total bacterial and total fungal counts for T.polium powder were $8.2 \times 10^{4} \mathrm{CFU} / \mathrm{g}$ and $3.1 \times 10^{4} \mathrm{CFU} / \mathrm{g}$ respectively. Samples that were irradiated with doses up to 5 kGy did not show any fungal counts, but there was a reduction of bacterial counts by $99.50 \%$ as compared to the control (0 KGy), while complete elimination was achieved at a dose level of 10 KGy and above( Table 3).

\section{DISSCUSION}

T d The microbial load of medicinal plants is influenced by their origin. Herbal drugs are subject to contamination by microorganisms from soil, air, water and post harvesting conditions maybe present potentially pathogenic microorganisms to man. Microbial contaminant in non-sterile pharmaceutical products may reduce or even inactivate the therapeutic activity of the product. Gamma radiation is one of the processes that allow achieving the highest standard of medicinal herbal product and food through the destruction of microorganism. Gamma irradiation has the ability to extend the shelf life and improve the hygienic quality of the product and also increase their effectiveness. As herbal medicinal products are complex mixtures which originate from biological sources, it is necessary to insure a constant and adequate quality [21].

To decontaminate and preserve these medicinal plants so as to get safer, natural and potent medicines, gamma radiation could be used. Exposing T.polium dry powder to gamma radiation with dosages from $5 \mathrm{kGy}$ to $15 \mathrm{kGy}$ increased the plant ethyl acetate extraction yield compared to non-irradiated control. The results showed that there are positive correlations between yield extract percentage and gamma radiation dose. The results of the present study confirm the findings of a previous study [29] which reported an increase in the extraction yields of Korean medicinal plants,

Arab J. Nucl. Sci. \& Applic. Vol. 53, No. 2 (2020) 
with increasing gamma radiation doses from 5 to 25 KGy. Similarly, several studies found that, an increase in extraction yield after treating with gamma radiation, and referred that to the degradation of some high molecular weight components or solubilization of some of the nonsoluble components of the plant material [22,30].

The present study indicated that TPC, TFC and TC contents in the ethyl acetate extract of $T$. polium were considerably increased in TPC, TFC and TC values in relevant to exposure dose $(5,10$, 15 and 20 KGy). The effect of gamma irradiation on the phenolic, flavonoid and tannins content of the $T$. polium was not conducted before. Many studies reported different effects of gamma radiation on plants phytochemical contents. Another study found that irradiation at $10 \mathrm{kGy}$ increases TPC and decreased TFC of Thymus algeriensis extract [31]. Also Ashouri, [32] reported an increase in total phenolic content in gamma irradiated Ferula gummosa as compared to the control. Khalaf, [33] confirmed that irradiated Cichorium intybus L. leaves and roots increased the levels of phenolics, flavonoids, enhanced the DPPH scavenging activity and antimicrobial activity against $B$. cereus, S. aureus, K. pneumonia and $P$. aeruginosa. A previous study [34] on irradiated Emblica offcinalis showed the increase in the level of phenolics, flavonoids, enhanced the $\mathrm{DPPH} \cdot$ scavenging activity and extraction yields. Another study for clove and nutmeg [35] reported an increase in tannin contents after irradiation at dose $15 \mathrm{KGy}$ and above. On the opposite side, gamma radiation may induce other effects on plants chemical contents. A study by Ghadi [36] found no effect of gamma radiation on TPC, while another study [37] revealed slight decreased of TPC and TFC values at $10 \mathrm{kGy}$.

Gamma radiation effect on the phytochemical contents may be attributed to different phenolic compounds present in different herbs. Hydrolysable tannins, which may be more susceptible to gamma-irradiation compared to the condensed tannin, could explain the increase in tannin contents which can be observed with increase of doses. Some studies have shown different effects that were attributed to the different phenolic compounds present in the different plant materials. Some of the materials have appreciable amounts of hydrolysable compounds, which may be more susceptible to gamma-irradiation compared to the condensed compounds present in other products. Accumulation of the phenolic compound in cells may be due to the release of phenolic compounds from glycosidic components and degrade the larger phenolic compounds into smaller ones by gamma radiation [38]. Briefly, by production of free radicals such as hydroxyl radicals, hydroperoxide radicals and hydrated electrons through the radiolysis of water, whereas, these radicals may break the glycosidic bonds of some compounds such as tetramer and hexamer that are present in plants, which increase the total phenolic and flavonoids content in irradiated plants [39].

The present study showed that the DPPH scavenging activities increased with gamma radiation, results in a significant increased antioxidant activity and decreased $\mathrm{IC}_{50}$ significantly in T.polium extract (Lower $\mathrm{IC}_{50}$ indicates to higher DPPH free radical scavenging activity) especially at $20 \mathrm{KGy}$. Similar results have previously revealed that gamma radiation significantly increased the antioxidant activity of Cichorium intybus roots and leaves [33]. While several published papers revealed the increase of DPPH radical- scavenging activity of extracts from irradiated herbs as in the Curcuma alismatifolia (Zingiberaceae) Leaves powder extract prepared from sample exposed to $20 \mathrm{~Gy}$ [40].

High antioxidant activity of plant extract may be attributed to the highest content of various phenolic compounds, therefore. These compounds are containing at least one hydroxyl aromatic ring system that can be easily oxidized and act as important units for donating electrons. Plants extract show the potent proton donating ability on DPPH' to produce DPPHH [41].

Gamma radiation caused no effect on the antibacterial activity of T.polium against S.aureus up to dose level of $20 \mathrm{KGy}$. No information is available in the literature on the effect of gamma irradiation on the antibacterial activity of T.polium. However, for other plant materials, the present study is in agreement with that of Pereira et al.[42] as the antimicrobial activity of the irradiated lemon verbena and Fagonia arabica extracts were not affected by gamma radiation treatment up to a dose level of $10 \mathrm{kGy}$. Another 
study confirmed that gamma-radiation has no effect on the antimicrobial activity of the Glycyrrhiza glabra roots up to 20 kGy [22]. Nigella sativa seed antimicrobial activity was not affected by gamma radiation up to $10 \mathrm{kGy}$ [43]. Another study [44], revealed that the antimicrobial activity of ciprofloxacin was not affected by gamma radiation treatment up to $100 \mathrm{kGy}$. Therefore, the significant effect of gamma radiation on the antibacterial activity may be due to some chemical changes in the structure of bioactive compounds upon irradiation at comparatively high doses. On the other hand, the results showed that the antibacterial activity of T.polium was significantly increased against P.aeroginosa with the increase of gamma radiation doses, a good agreement on the content of phenolic compounds (responsible for antibacterial activity) among the non-irradiated and irradiated samples was found, inferring that these compounds were stable and were not decomposed by the irradiation [33]. Also gamma radiation affects chemical modifications in compounds, enhancing their action against the $S$. aureus.

The results of microbial load count of the nonirradiated samples of T.polium were highly contaminated with bacteria and fungi at the levels of $8 \times 10^{4} \mathrm{CFU} / \mathrm{g}$ and $3 \times 10^{4} \mathrm{CFU} / \mathrm{g}$, respectively. These values exceeded the level of $1.0 \times 10^{4} \mathrm{CFU} / \mathrm{g}$ reported by WHO [45] as the maximum permissible total count level. The high contamination level may be due to the high natural micro flora of the herbs as well as the general conditions during their cultivation, harvesting, drying, handling, processing, storage, distribution and sales. T.polium irradiated with 5, 10, 15 and 20 KGy of gamma radiation had significantly reduced the microbial count. Whereas, gamma radiation at a dose level of $5 \mathrm{kGy}$ decreased the total microbial load of the plant by $98.5 \%$, it was $100 \%$ at a dose level of $10 \mathrm{kGy}$. This result agrees with the study of Sofowora et al. [46]. Gamma irradiation kills the microbes through water. Ionization of water is achieved through the excruciating the molecules of water into hydrogen, hydroxyl and oxygen radicals. The most important target of ionizing radiation in a microorganism is the DNA molecule. Therefore, the free radicals combine with the microbial DNA and destroy or deactivate them [47].

\section{References}

(1) Z. Sabet, M.Roghani, M.Najafi and Z.Maghsoudi. "Antidiabetic effect of Teucrium polium aqueous extract in multiple low-dose streptozotocin -induced model of type 1 diabetes in rat", $\mathrm{J}$ Basic Clin Physiol. 1(2), (2013), 34-38.

(2) S. Bahramikia, and R. Yazdanparast. "Phytochemistry and medicinal properties of Teucrium polium L.(Lamiaceae)", Phytother Res., 26(11), (2012), 1581-1593.

(3) B. Saad, H. Zaid, S. Shanak and S. Kadan, "Anti-diabetes and anti-obesity medicinal plants and phytochemicals", (2017), Springer international publishing AG.

(4) H. Forouzandeh, M. E. Azemi, I. Rashidi, M. Goudarzi and H. Kalantari, "Study of the protective effect of Teucrium polium L. extract on acetaminophen-induced hepatotoxicity in mice." IJPR 12(1) (2013),123.

(5) Ö. Züleyha, T. kiliç, S. çarikçi and H. Yilmaz, "Investigation of phenolic compounds and antioxidant activity of Teucrium polium L. decoction and infusion", Balıkesir Üniversitesi Fen Bilimleri Enstitüsü Dergisi: (2017)1-7.

(6) S. Kadan, Y. Sasson, R. Abu-Reziq, B. Saad, S. Benvalid, T. Linn, G. Cohen, H. Zaid, " Teucrium polium extracts stimulate GLUT4 translocation to the plasma membrane in L6 muscle cells" Adv Med Plant Res., 6(1), (2018), 1-8.

(7) C. Moustapha, , T. Hasen and M. Waleed, "Chemical Constituents of Teucrium Polium L. var. Mollissimum: Hand-Mazz.", JJC, 146(604), (2011), 1-7.

(8) T. Lograda, M. Ramdani, P. Chalard and G. Figueredo. "Antibacterial activity of essential oils of Rosmarinus officinalis from Eastern Algeria", GJRMI, 3(6), (2014), 232.

(9) H. Rasekh, M. Khoshnood-Mansourkhani and M. Kamalinejad, "Hypolipidemic effects of Teucrium polium in rats", Fitoterapia, 72(8), (2001), 937-939.

(10) F. Sheikhbahaei, M. Khazaei and S. N. Nematollahi-Mahani, "Teucrium polium extract enhances the anti-angiogenesis effect

Arab J. Nucl. Sci. \& Applic. Vol. 53, No. 2 (2020) 
of tranilast on human umbilical vein endothelial cells", Adv Pharm Bull., 8(1), (2018), 131.

(11) Belmekki, N., N. Bendimerad and C. Bekhechi, "Chemical analysis and antimicrobial activity of Teucrium polium L. essential oil from Western Algeria", J. Med. Plants Res.,7(14), (2013), 897-902.

(12)

A.Ota, and N. P. Ulrih, "An overview of herbal products and secondary metabolites used for management of type two diabetes", FRONT PHARMACOL, 8, (2017), 436.

(13) G. Rahim, R. Qureshi, M. Arshad and M. Gulfraz, "Phytochemical analysis and antioxidant properties of Teucrium stocksianum flower from Malakand Division, Pakistan", INT J AGRIC BIOL., 15(2), (2013).

(14) F. Sharififar, G. Dehghn-Nudeh and M. Mirtajaldini "Major flavonoids with antioxidant activity from Teucrium polium L", Food Chem.,112(4), (2009), 885-888.

(15) M. B. Sghaier, W. Bhouri, A. Neffati, J. Boubaker, I. Skandrani, I. Bouhlel, S. Kilani, L. Chekir-Ghedira and K. Ghedira, "Chemical investigation of different crude extracts from Teucrium ramosissimum leaves. Correlation with their antigenotoxic and antioxidant properties.", Food Chem Toxicol., 49(1), (2011), 191201.

(16) S. Hachicha, S. Barrek, T. Skanji, H. Zarrouk and Z. Ghrabi, "Fatty acid, tocopherol, and sterol content of three Teucrium species from Tunisia.", CHEM NAT COMPD, 45(3), (2009), 304-308.

(17) M. Bruno, M. L. Bondì, S. Rosselli, A. Maggio, F. Piozzi and N. A. Arnold L. C.,, "Neoclerodane Diterpenoids from Teucrium m ontbretii Subsp. I ibanoticum and Their Absolute Configuration.", J NAT PROD., 65(2), (2002), 142-146.

(18) A. Bianco, A. Ramunno, A. M. Serrilli, M. L. Castro, B. Mauro and M. Serafini, "Phytochemical characters of Teucrium marum from Sardinia: an endemic plant", Nat. Prod. Res., 18(6), (2004), 557564.
(19)

F. Piozzi, M. Bruno, S. Rosselli and A. Maggio, "Advances on the chemistry of furano-diterpenoids from Teucrium genus", HETEROCYCLES, 65, (2005), 1221-1234.

(20) R. R. Satomi, Soriani and T. d. J. A. Pinto, "Descontaminação de drogas vegetais empregando irradiação gama e óxido de etileno: aspectos microbianos e químicos.", REV BRAS CIENC FARM, 41(4), (2005), 445-450.

(21) I. S., Arvanitoyannis, A. Stratakos and E. Mente, "Impact of irradiation on fish and seafood shelf life: a comprehensive review of applications and irradiation detection", Crit Rev Food Sci Nutr., 49(1), (2008), 68-112.

(22) K. F. Khattak, and T. J. Simpson, "Effect of gamma irradiation on the extraction yield, total phenolic content and free radical-scavenging activity of Nigella staiva seed.", Food Chem.,110(4), (2008), 967-972.

(23) V. L. Singleton, R. Orthofer and R. M. Lamuela-Raventós," Analysis of total phenols and other oxidation substrates and antioxidants by means of folin-ciocalteu reagent", METHOD ENZYMOL., 299, (1999), 152-178.

(24) A. Ismail, A. Yao, E. Yeo, K. LaiKuan and J. Soon-Yew "Occupational stress features, emotional intelligence and job satisfaction: An empirical study in private institutions of higher learning.", Negotium, 6(16), (2010), 5-33.

(25) S. Polshettiwar, R. Ganjiwale, S. Wadher and P. Yeole, "Spectrophotometric estimation of total tannins in some ayurvedic eye drops.", Indian J. Pharm. Sci. , 69(4), (2007), 574.

(26) K. Yamasaki, A. Hashimoto, Y. Kokusenya, T. Miyamoto and T. Sato, "Electrochemical method for estimating the antioxidative effects of methanol extracts of crude drugs.", Chem. Pharm. Bull., 42(8), (1994), 1663-1665.

(27) P. Murray, E. Baron, M. Pfaller, F. Tenover and R. Yolken In "Manual of 
clinical Microbiology", 6, (1999), Washington, DC: ASM.

(28) Y. Velioglu, G. Mazza, L. Gao and B. Oomah, "Antioxidant activity and total phenolics in selected fruits, vegetables, and grain products.", J. Agric. Food Chem., 46(10), (1998), 4113-4117.

(29)

P. C. Gupta, N. Garg and P. Joshi, "Effect of gamma irradiation on the extraction yield and microbial contamination of medicinal plants.", Internet J. Food Saf, 13, (2011), 351- 354.

(30) N. A. Hasbullah, R. M. Taha, A. Saleh and N. Mahmad "Irradiation effect on in vitro organogenesis, callus growth and plantlet development of Gerbera jamesonii", Hort. Bras., 30(2), (2012), 252-257.

(31) S. Douar-Latreche, O. Benchabane, N. Sahraoui, M. Hazzit, F. Mouhouche and A. Baaliouamer "Effect of Gamma Irradiation on the Chemical Composition and Antioxidant Activity of Thymus algeriensis Extracts", J ESSENT OIL BEAR PL., 21(2), (2018), 449-461.

(32)

A. Ashouri Sheikhi, H. Hassanpour, P. Jonoubi, M. Ghorbani Nohooji and M. Nadimifar "The Effect of Gamma Irradiation on In vitro Total Phenolic Content and Antioxidant Activity of Ferula gummosa Bioss.", J. Med. Plants, 3(59), (2016), 122131.

H. A. Khalaf, R. M. El-Saadani, A. I. El-Desouky, M. H. Abdeldaiem and M. E. Elmehy "Antioxidant and antimicrobial activity of gamma-irradiated chicory (Cichorium intybus L.) leaves and roots.", J FOOD MEAS CHARACT., 12(3), (2018), 1843-1851.

(34) K. Khattak, "Proximate composition, phytochemical profile and free radical scavenging activity of radiation processed Emblica officinalis.", INT FOOD RES J., 20(3), (2013).

(35)

K. Harrison, and L. Were "Effect of gamma irradiation on total phenolic content yield and antioxidant capacity of almond skin extracts.", Food Chem., 102(3), (2007), 932- 937.

F. E. Ghadi, A. R. Ghara and T.
Ghanbari, "Effect of gamma irradiation on the total phenolic content and free radicalscavenging activity of Iranian date palm Mazafati (Phoenix dactylifera L.).", Int. J. Lat. Resear. Sci. Tech., 4, (2015), 149-153.

(37)

K. S. Moosavi, S. Hosseini, G. Dehghan and A. Jahanban-Esfahlan "The effect of gamma irradiation on phytochemical content and antioxidant activity of stored and none stored almond (Amygdalus communis L.) hull.", Pharm. Sci., 20(3), (2014), 102.

(38)

P. Hussain, S. Chatterjee, P. Variyar, A. Sharma, M. Dar and A. Wani, "Bioactive compounds and antioxidant activity of gamma irradiated sun dried apricots (Prunus armeniaca L.).", J. Food Compos. Anal., 30(2), (2013), 59-66.

(39)

$\mathrm{X}$. Fan, and K. Mastovska, "Effectiveness of ionizing radiation in reducing furan and acrylamide levels in foods.", J. Agric. Food Chem., 54(21), (2006), 8266- 8270.

(40) S. Taheri, T. Abdullah, E. Karimi, E. Oskoueian and M. Ebrahimi, "Antioxidant capacities and total phenolic contents enhancement with acute gamma irradiation in Curcuma alismatifolia (Zingiberaceae) leaves.", Int. J. Mol. Sci., 15(7), (2014), 13077-13090.

(41) Shah, A., F. Masoodi, A. Gani and B. A. Ashwar, "Effect of $\gamma$-irradiation on antioxidant and antiproliferative properties of oat $\beta$-glucan.", Radiat. Phys. Chem., 117, (2015), 120-127.

(42)

E. Pereira, A. I. Pimenta, R. C. Calhelha, A. L. Antonio, L. Barros, C. Santos-Buelga, S.C. Verde and I. C. Ferreira, "Infusions of gamma irradiated Aloysia citrodora L. and Mentha $\mathrm{x}$ piperita L.: Effects on phenolic composition, cytotoxicity, antibacterial and virucidal activities.", IND CROP PROD., 97, (2017), 582-590.

(43) K. Khattak, and A. L., "Ihsanullah Effect of gamma radiation on antimicrobial compounds of Nigella sativa." Proceedings of the National Executive Symposium on Technologies Developed for Commercialisation. Challenges and

Arab J. Nucl. Sci. \& Applic. Vol. 53, No. 2 (2020) 
Opportunities, NIFA Peshawar Pakistan. (2004).

(44) A., Al-Mohizea, I. El-Bagory, I. Alsarra, F. Al-Jenoobi and M. Bayomi, "Effect of gamma radiation on the physicochemical properties of ciprofloxacin in solid state.", J DRUG DELIV SCI TEC., 17(3), (2007), 211-215.

(45) WHO, Guidelines for Safe Recreational-water Environments: Coastal and Freshwaters. Draft for Consultation, World Health Organization, (1998), Geneva.

(46) A. Sofowora, E. Ogunbodede and A. Onayade "The role and place of medicinal plants in the strategies for disease prevention.", Afr J Tradit Complement Altern Med., 10(5), (2013), 210-229.

(47) H. Abdel-Khalek, "Effect of gamma irradiation on the microbial, chemical quality and the biological activity of some spices and herbs", PhD thesis , Cairo University, Egypt, (2008). 